\title{
Determination of boiling curve of spray cooling by IR thermography
}

by J.-M. Buchlin ${ }^{1}$, J.-B. Gouriet ${ }^{1}$, M. Delsipée ${ }^{1}$ and M. Renard ${ }^{2}$

${ }^{1}$ von Karman Institute of Fluid Dynamics, 1640, Rhode-Saint-Genèse, Belgium

2 Drever International,4031 Angleur, Belgium

\begin{abstract}
An experimental IR thermography technique allowing the determination of the boiling curve during water spray cooling of a hot thin moving steel strip is presented. The dedicated test facility, called SprayCooling, is described. The thin thermal foil approach is combined with the strip temperature measurement obtained by IR camera. The accuracy of the method relies mainly upon the estimation of the local derivative of the temperature profile. Therefore, smooth temperature profiles are obtained by thermogramme averaging and filtering techniques. Finally, the heat transfer coefficient is obtained for strip temperature varying from $20^{\circ} \mathrm{C}$ to more than $400^{\circ} \mathrm{C}$ and at different water mass fluxes. The study deals with an experimental technique based on the use of the IR thermography to determine the heat transfer coefficient characterizing the cooling of a hot moving steel strip by water sprays.
\end{abstract}

\section{Introduction}

Innovation in automotive industry requires the use of high-resistance steels. The production of AHSS grades in continuous annealing lines and hot dip galvanizing lines leads to new developments in the furnace technology. Drever International is developing a flexible and fast cooling technology, D-Storm $®$, by means of liquid cooling offering high cooling rates and control of the thermal cycle of the strip. The schematic in figure 1 illustrates the principle of the process.

With the aim to optimize the design of such quenching units, the von Karman Institute (VKI) had developed in collaboration with Drever International an engineering code [1]. The modelling relies upon the generalisation of the boiling curve specific to spray cooling [2-7]. To extend the applicability of this design tool to a wide range of spray nozzles and nozzle arrangements the research project SprayCooling has been undertaken with the objective to determine the correlation between the heat transfer coefficient and the operating conditions.

The paper describes the method to obtain the heat transfer coefficient, the test facility and the IR measurement technique involved as well. Then, results demonstrating the cooling performance of this type of quenching are presented. Finally, conclusive remarks on the progress of the research project are made and future work is introduced.

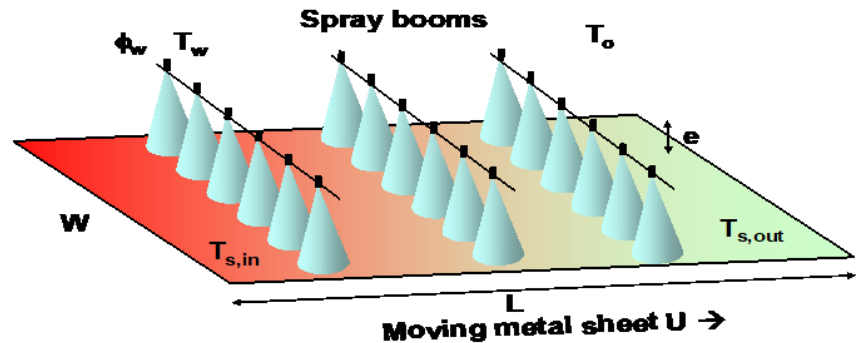

Fig. 1. Schematic of strip cooling by water spray arrangement

\section{Thermal modelling}

When passing through the spray array, the moving strip undergoes different heat transfer mechanisms: transport by advection, conduction due to thermal gradients, thermal radiation, qrad, and the most important of all convective heat transfer produced by the water droplets, $q_{s}$. Because the strip is regarded as a very thin foil of thickness $e$, the thermal balance equation can be written as follows:

$$
C U e \frac{\partial T}{\partial x}=e \nabla \cdot(k \nabla T)+q_{s}+q_{r a d}
$$

Where $U$ is the strip velocity. $C$ and $k$ the heat capacity and thermal conductivity of the steel, respectively.

In the present investigation, the thickness of the strip does not exceed $0.3 \mathrm{~mm}$ and despite the high value of the convective heat transfer coefficient, the Biot number remains rather small so that the strip temperature can be regarded 
as quasi uniform through the steel thickness. Moreover, simulation carried out with the code SprayCool [1] shows that the contributions of the conduction and radiation flux are three orders of magnitude smaller than the convective term. Therefore, the recast of Eq. (1) leads to the expression of the local heat transfer coefficient due to spray:

$$
h_{s}(x)=\frac{C(T) \cup e \frac{d T}{d x}(x)}{\left[T_{s}-T(x)\right]}
$$

From Eq. (2) one notes that the measurement of $T(x)$ and the calculation of its derivative provides access to the knowledge of the axial distribution $h_{s}(x)$. Note that in Eq.(2) the heat capacity of the steel is considered varying with the strip temperature.

\section{Experimental approach}

\subsection{Test facility}

A dedicated close-loop test facility, called SprayCooling, has been designed and constructed. It mimics a semi industrial prototype. A simplified layout and some views are shown in figure 2.

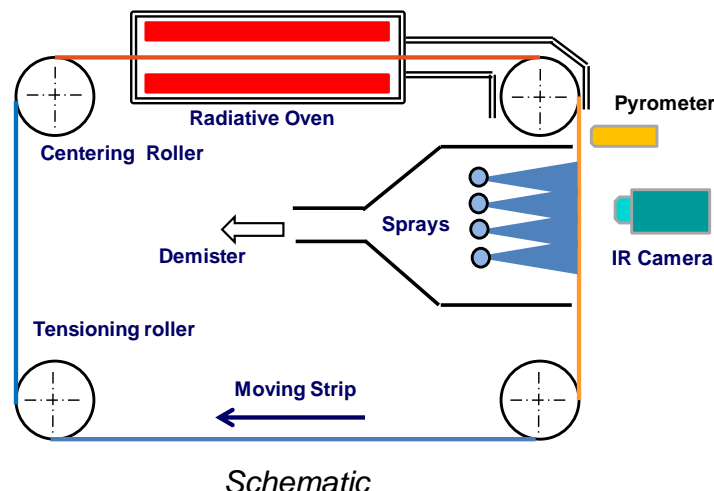

Schematic

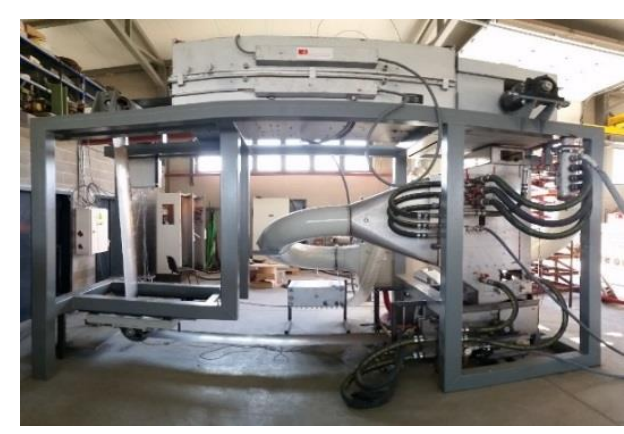

General view

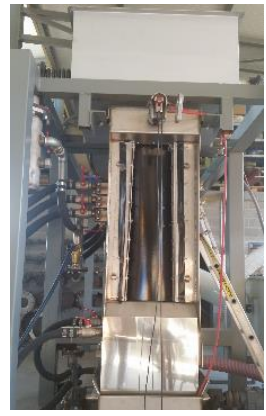

Test section

Fig .2. The test facility SprayCooling

A metal strip of $0.253 \mathrm{~mm}$ thick $(e)$ and $0.33 \mathrm{~m}$ wide, and black painted (emissivity of 0.89 determined by using a 2-color pyrometer) is continuously moving at a given speed ranging between 0.2 and $0.6 \mathrm{~m} / \mathrm{s}$. The strip can be heated in a radiative oven up to high temperature of $400^{\circ} \mathrm{C}$ to $800^{\circ} \mathrm{C}$ and passes through a cooling section composed of an arrangement of water spray nozzles. The droplets only impinge on one side of the strip while the other side is scanned by an infrared camera, which allows the determination of the strip temperature evolution in the cooling unit. The strip is dried downstream by a series or air knife and returns to the oven section. A demister system allows the permanent removal of the droplets in suspension around the sprays.

\subsection{Measurement techniques and data processing}

The dependency of the steel heat capacity on the temperature has been determined by differential scanning calorimetry. The measures have been performed with the thermal analyser STA 449 F3 Jupiter, NETZSCH according to the DIN51007 norm in the range $25^{\circ} \mathrm{C}$ to $950^{\circ} \mathrm{C}$.

A bichromatic pyrometer measures the temperature on the centerline of the strip at the inlet of the cooling section. The IR camera is operating within $7.5-14 \mu \mathrm{m}$ at $50 \mathrm{~Hz}$ and provides frames of $640 \times 480$ pixels.

The accuracy of the method relies mainly upon the estimation of the local derivative, $d T / d x$, of the temperature profile. Consequently, a peculiar attention is given to the sensitivity of the results to the spatial resolution of the measurement. The camera is located at $0.75 \mathrm{~m}$ from the strip to be able capturing the entirety of the temperature profile with a spatial resolution of $0.5 \mathrm{~mm} /$ pixel. Figure 3 a shows a typical false-color thermogramme obtained after application of the grey-intensity/temperature calibration curve. The thermogramme clearly indicates the beginning of the cooling zone and that the cooling is fairly uniform in the spanwise direction despite the difficulty to assess perfect liquid flow distribution at the impact.

The processing of thermogrammes is based on the following procedure. Three stripes of $10 \mathrm{~mm}$ wide and separated of $50 \mathrm{~mm}$, are defined on the thermogramme as shown in figure $3 \mathrm{~b}$. In each stripe, the vertical temperature 
profiles (about 10) are spatially averaged. The mean vertical profile of each stripe is then filtered by means of a digital lowpass FIR filter of 34 order with a cut-of frequency equal to $1 / 3$ of the signal frequency.

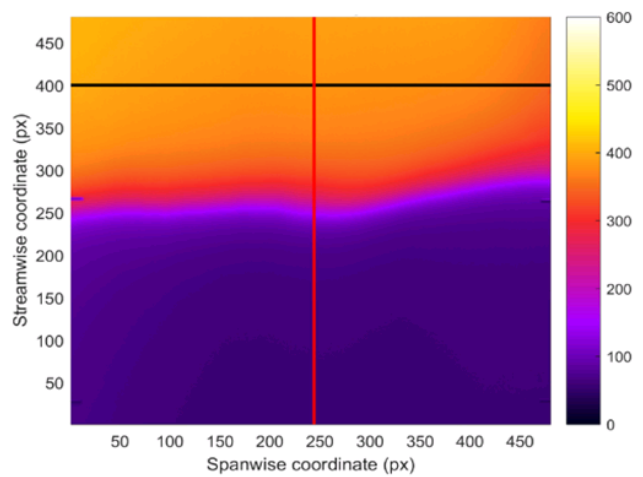

(a) Temperature mapping

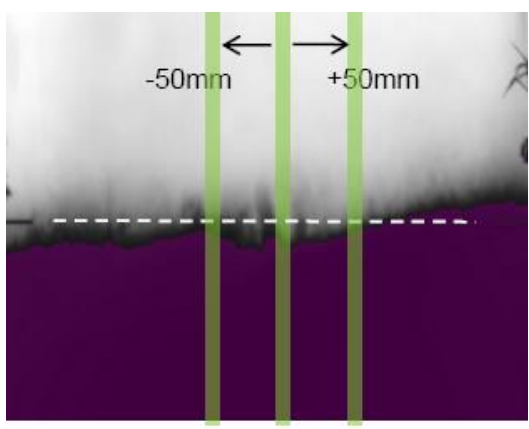

(b) Grey intensity mapping

Fig. 3. Typical thermogrammes

Finally, a time average of 1000 successive profiles is performed. Figure 4a shows the axial temperature evolutions along the three stripes as the strip is passing though the cooling unit. $\mathrm{X}=0$ corresponds to the position of the spray ramp. From such thermal profiles, the local temperature derivative is calculated by $2^{\text {nd }}$-order central difference, which allows the determination of the heat flux, $q_{s}$, as plotted in figure $4 \mathrm{~b}$.

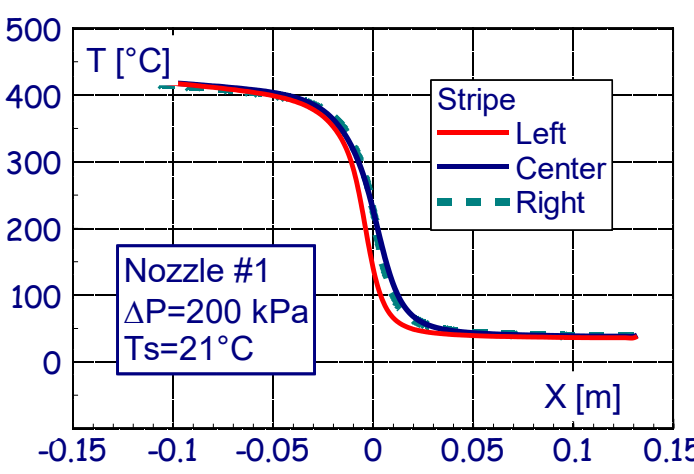

(a) Axial temperature distribution

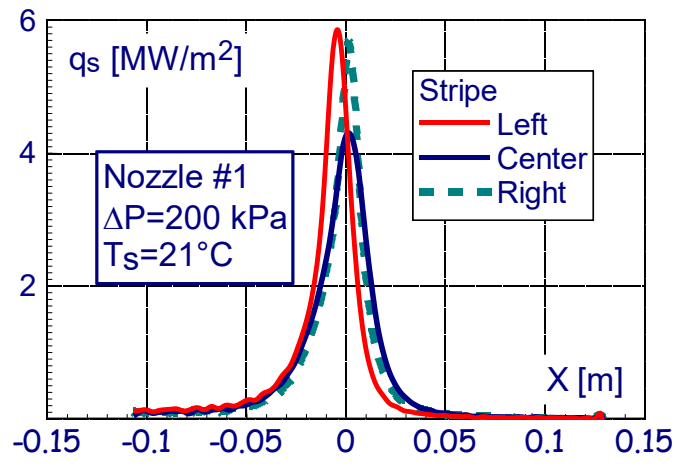

(b) Axial heat flux distribution

Fig. 4. Cooling results

One notes that, despite the fairly good lateral uniformity observed on the thermogramme in figure $3 a$, important differences of the critical heat flux can be measured due to spanwise local mass flux variations

\section{Illustrative results}

Two pneumatic atomizing flat fan nozzles have been tested. They are characterized by flow number of $8.1 \times 10^{-5}$ $\ell / \mathrm{s} \cdot \sqrt{\mathrm{Pa}}$ and $7 \cdot \ell / \mathrm{s} \cdot \sqrt{\mathrm{Pa}}$, respectively. They are equally spaced on a single ramp, which is positioned at $0.27 \mathrm{~m}$ from the strip. Same pressure is set for air and water in the range of $200 \mathrm{kPa}$ to $400 \mathrm{kPa}$. The water temperature is adjusted to fix the subcooling between $35^{\circ} \mathrm{C}$ and $80^{\circ} \mathrm{C}$. The illustrative results are given by limiting the analysis of the cooling performance to the central region of the strip.

Good repeatability can be appreciated for the two nozzles in figure 5, where the longitudinal temperature evolution of the strip and the extracted boiling curve are plotted for two successive tests. The largest discrepancy is obtained for the nozzle \#1 with a relative variation of $6 \%$ at the critical heat flux.

One can notice that the strip is cooled from $400^{\circ} \mathrm{C}$ to the water temperature on a rather small distance indicating that cooling rate of about $650^{\circ} \mathrm{C} / \mathrm{s}$ can be readily achieved. The type of boiling curve is in very good agreement with data published in literature such as $[8,9]$. 

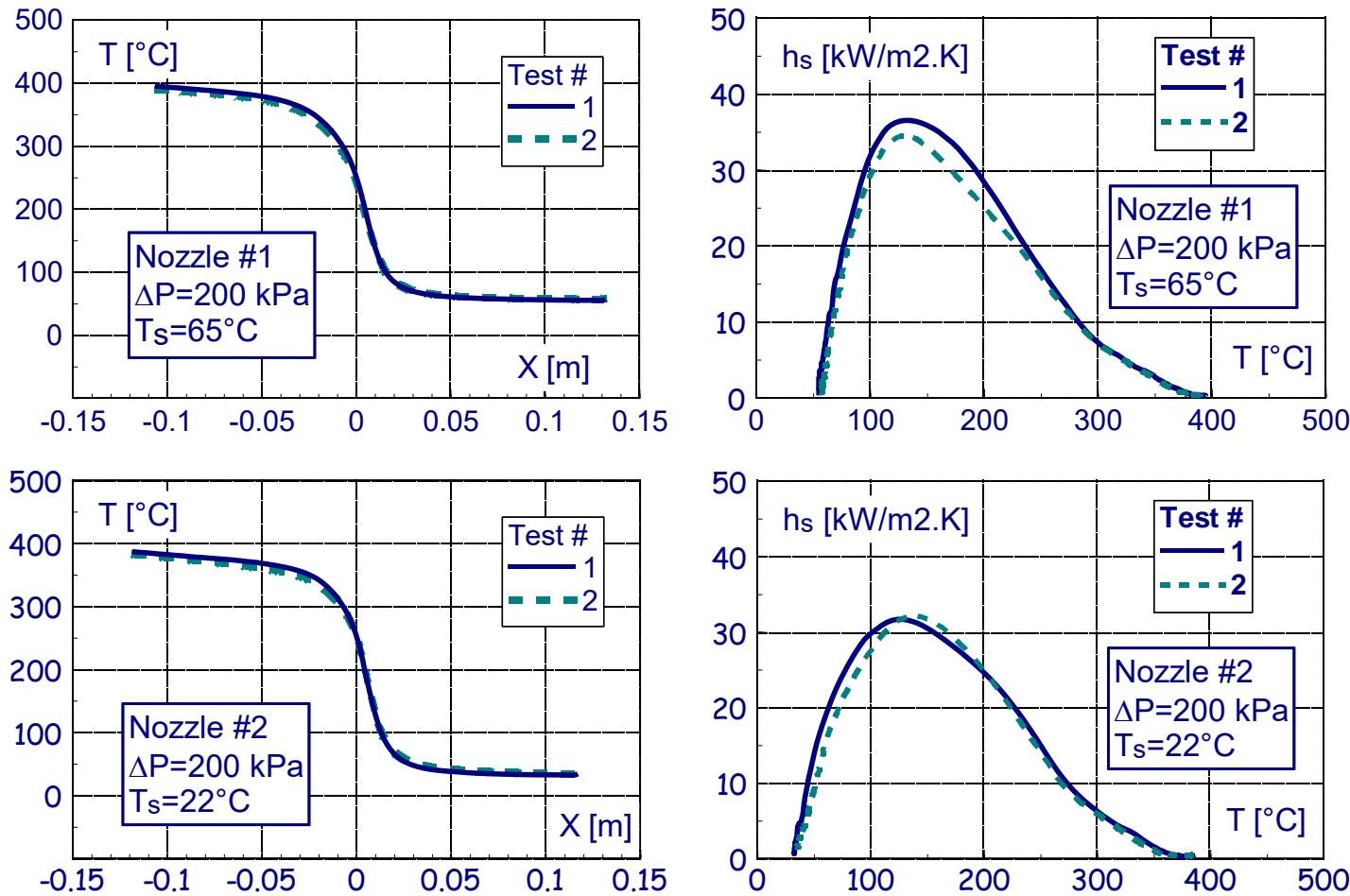

Fig. 5. Repeatability level

The increase of the supply pressure leads to a rise of the water mass flux and improves the cooling efficacy of the sprays as depicted in figure 6 . The heat transfer peak remains located at approximatively the same strip temperature of $130^{\circ} \mathrm{C}$ and its amplitude augments linearly with the square root of the pressure $\left(R^{2}=95 \%\right)$.

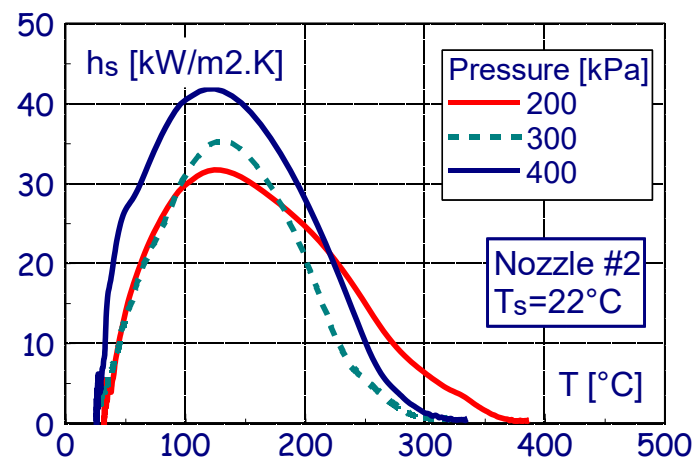

Fig. 6. Effect of the pressure.

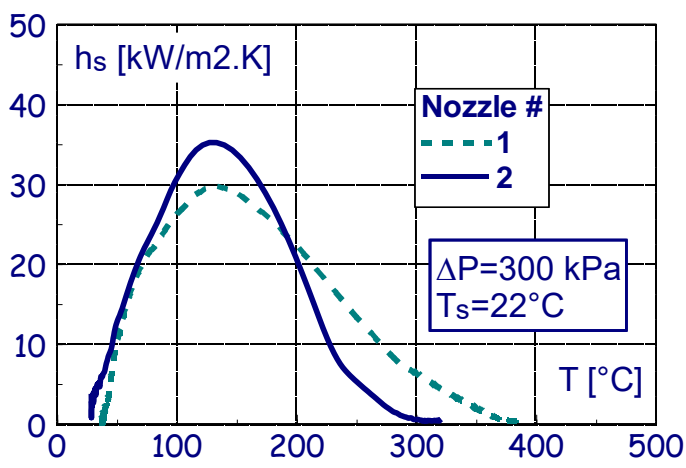

Fig. 7. Effect of the nozzle design.

Figure 7 shows that the nozzle design can also affects the cooling features of the strip. Indeed, working at the same operating conditions and although having very close features, nozzle \#2 provides an increase of $20 \%$ of the critical heat flux compared to nozzle \#1.

The effect of the degree of subcooling has not been deeply analyzed in the literature so far and the scarce data published are often opposing [9]. Figure 8 displays the results obtained for two degrees of subcooling. It is observed that a decrease of $50 \%$ of $\Delta T_{\text {sub }}$ may only result in an increase of $10 \%$ of the critical heat flux. However, that corresponds to an augmentation of $50 \%$ of the maximum heat transfer coefficient because $T-T_{s}$ becomes smaller as the subcooling decreases. The explanation of such a rather unexpected behavior might be found in the effect of the evaporation. As the liquid temperature approaches the saturation condition (low subcooling), liquid evaporation becomes important. Not only the droplet temperature drops but their size decreases. Thereby, few studies have indicated that smaller droplet sprays might afford better cooling efficacy $[2,10]$. From the authors view, such a result is only valid for mist cooling at low mass flux condition and that the subcooling effect is not clarified yet. It does demand additional investigation. 

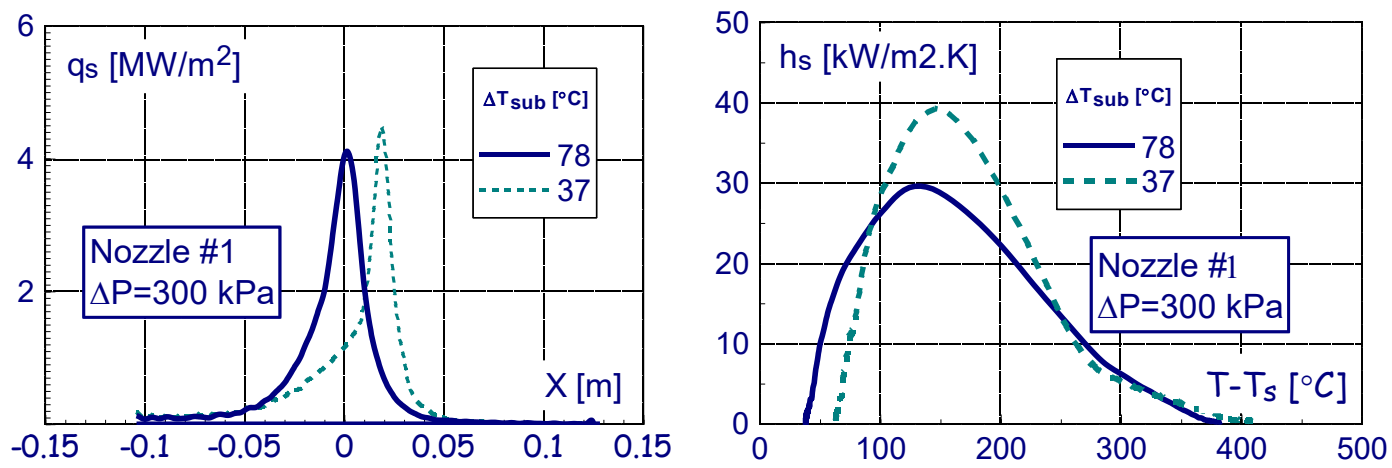

Fig. 8. Effect of degree of subcooling

\section{Conclusions}

Spray cooling of hot thin moving strip is experimentally studied on a dedicated semi industrial test facility.

The measurement technique relies upon an original thermofoil theory combined with quantitative infrared thermography. It requires a proper processing of the IR thermogramme involving spatial and time average with efficient filtering.

Tests performed on two types of pneumatic atomizing nozzles show good repeatability of experiments with a maximum of $6 \%$ of deviation. They also underline the positive effect of the operating pressure and the impact of the nozzle design.

The controverted influence of subcooling is also addressed. Preliminary tests show that a $50 \%$ decrease of subcooling leads to only $10 \%$ increase of critical heat flux, which could be due to the subsequent evaporation on the droplet diameter. However, this issue requires more investigation to be elucidated.

\section{NOMENCLATURE}

$\begin{array}{ll}\begin{array}{l}\text { heat capacity } \\ \text { thickness }\end{array} & \left(\mathrm{J} / \mathrm{m}^{3} \cdot \mathrm{K}\right) \\ \text { heat transfer coefficient } & (\mathrm{m}) \\ \text { thermal conductivity } & \left(\mathrm{W} / \mathrm{m}^{2} . \mathrm{K}\right) \\ \text { heat flux } & \left(\mathrm{W} / \mathrm{m}^{\mathrm{K}}\right) \\ \text { temperature } & \left(\mathrm{W} / \mathrm{m}^{2}\right) \\ \text { velocity } & \left({ }^{\circ} \mathrm{C}\right) \\ \text { axial coordinate } & (\mathrm{m} / \mathrm{s}) \\ \text { spanwise coordinate } & (\mathrm{m}) \\ & (\mathrm{m}) \\ \text { subscript } & \\ \text { rad radiant } & \\ \text { s spray } & \end{array}$

\section{ACKNOWLEDGMENT}

The authors are indebted to the DGO6 of the Walloon region for its continuous support along this research programme conducted in the frame of the Convention RW- 7233.

\section{REFERENCES}

[1] [Buchlin J.-M., Sanz J. and Renard M.; Modelling of spray cooling of high-temperature moving metal strips, DITICE Workshop, Bergamo, Italy -19th May 2006.

[2] Bolle L., and Moureau J.C., 1982, Sprays cooling of hot surfaces, in Multiphase Science and Technology, Vol. 1, pp. 1-97, Hemisphere, New-York.

[3] Mitsutsuka, M. and Fukuda, K.; 1983, Cooling characteristics and heat transfer coefficients during Water-Spray Cooling of Hot Steel Plate, Tetsu-To-Hagane / Journal of the Iron and Steel Institute of Japan, vol. 69, No. 2, pp. 76-81 
[4] Mitsutsuka, M.; 1983, Heat Transfer Coefficients in the Surface Temperature Range of 400 to $800^{\circ} \mathrm{C}$ during Water Spray Cooling of Hot Steel Product, Tetsu-To-Hagane / Journal of the Iron and Steel Institute of Japan, Vol. 69. No. 2, pp. 82-88.

[5] Bamberger, M. and Prinz, B.; 1986, Determination of the heat transfer coefficients during water cooling of metals, Materials Science and Technology, Vol. 2, pp. 410-415.

[6] Yao S.C. and Choi K. J.;1987, Heat transfer experiments of mono-dispersed vertically impacting sprays, Int. J. Multiphase Flow, Vol. 13, No. 5, pp. 639-648.

[7] Ciofalo M., Di Piazza I. and Brucato V.; 1999, Investigation of the cooling of hot walls by liquid water sprays-, International Journal of Heat and Mass Transfer, 42, pp. 1157-1175.

[8] Golovko O., Frolov I., Rodman D., Nürnberger F., Grydin O. and Schaper M.; 2014, Spray cooling of extruded EN AW-6082 aluminium alloy sheets: spatial heat transfer coefficients-, Forsch Ingenieurwes, DOI 10.1007/s10010014-0181-y= 78, pp. 131-137.

[9] R. Guo et al. Investigation of heat transfer on 2024 aluminum alloy thin sheets by water spray quenching. Experimental Thermal and Fluid Schience,2016, vol. 72, 249-257.

[10] K. Takeuchi, J. Senda and K. Yamada. Heat transfer characteristics and the breakup behavior of small droplet impinging upon a hot surface. ASME-JSME Thermal Engineering Joint Conference, 1983, Vol. 1, pp. 165-172. 